\title{
Reversion of Permethrin Resistance in Field Strains and Selection for Azinphosmethyl and Permethrin Resistance in Pink Bollworm (Lepidoptera: Gelechiidae)
}

\author{
Abdelgadir A. Osman. Theo F. Hatson and Sakuntala Sivasupramaniam
}

\begin{abstract}
Rearing of (wo field strains (Marana. Yuma) of pink bollworm. Peclinophora gossypiella (Saunders). from Arizona under conditions free of insecticides resulted in reversion of resistance (in adults) in four and five generalions. respectively. to levels close to that found in the susceptible laboratory strain. Permethrin resistance in these ficld strains is unstable and is apparently in its early phase of development. Results suggest that monitoring of pink bollworm resistance in field strains reared in the lahoralory should be performed in the $F_{1}$ generation. Subsequent selection studies were performed on both larval and adult stages to investigale the capacity of the pink hollworm to develop resistance in both life stages. Fourteen generations of selection of larvae and adulis with azinphosmethyl produced 1.9- and 1.6-fold tolerance. respectively. in the adult stage. Sixteen generations of larval selection with permethrin generated 9.7-fold resistance in adults. while 14 generations of adult selection produced 8.8-fold resistance in adults. Azinphosmethyl evidently possesses a low degree of selectivity for development of resistance in pink bollworm adults. Selection of larrae with both azinphosmethyl and permethrin seemed 10 generale higher levels of colerance in larvae than in adults.
\end{abstract}

\section{Introduction}

Pink bollworm, Pectillophora gossypiella (Saunders), is the most serious pest of cotton in Arizona. Carruth \& Moore (1973) reported that serious secondary pest outbreaks result from numerous insecticide applications used in achieving control of the pink bollworm. Recently, resistance to pyrethroids has been detected in pink bollworm populations in Arizona and southern California (Bariola 1985. Haynes et al. 1986).

The objectives of our study were to determine the pattern of reversion of permethrin resistance in field populations which have been released from selection pressure, and to investigate the capacity of field strains of pink bollworm to develop resistance to azinphosmethyl and permethrin in larvae and adults.

\section{Materials and Methods}

Insecticides. Technical grade permethrin (Pounce, 98.4\%, F.M.C. Corp., Agricultural Chemical Division, Middleport, New York) and technical grade azinphosmethyl (Guthion, 91\%, Mobay Chemical Corp., Agricultural Chemical Division, Kansas City, MO.) were tested. Serial dilutions of the two chemicals were prepared in redistilled acetone and refrigerated at $5^{\circ} \mathrm{C}$. Fresh preparations 
were made at two-monthly intervals.

Rearing of Pink bollworm Strains. Two field strains were collected from Marana and Yuma, Arizona. The rearing procedure used at the pink bollworm rearing facility at the Western Cotton Research Laboratory, USDA-ARS, Phoenix, Arizona (Bartlett \& Wolf 1985), was modified for small colonies. Adults were held in $230 \mathrm{ml}$ paper ice cream cups and stored in environmental chambers set at a temperature of $26 \pm 1^{\circ} \mathrm{C}$ and a photoperiod of $14: 10$ (L:D). Humidity was maintained at a constant level using free water held in a plastic tray $(40$ by 27 by $9 \mathrm{~cm})$. The cardboard lids of the rearing cups were replaced with wire-mesh lightly glued around the circumference. The moths were fed with 10\% sucrose solution that diffused through cotton plugs ( $30 \mathrm{~mm}$ length, Johnson and Johnson) inserted through an opening in the mesh-lined cover. These containers were used to hold pupae and adults and as rearing cups throughout the study.

The container lids were covered with squares of coarse white paper and weighted down with metal rings. The wax coating on the inside of the cups helped prevent oviposition on container walls. The paper squares served as oviposition sites and the egg sheets were changed every two days. These sheets were stored in environmental chambers for three to four days, and then transferred 101.81 cardboard cartons containing artificial diet provided by the Western Cotton Research Laboratory. USDA-ARS, Phoenix, Arizona. These cartons were placed in plastic boxes ( 40 by 27 by $9 \mathrm{~cm})$ lined with a three to four $\mathrm{cm}$ layer of styrofoam (to provide a substrate for pupation). Pupae were collected periodically and held in bioassay cups in environmental chambers for adult emergence.

Bioassay Procedures: (i) Adults. Assays were performed with 2- to 3-day-old moths of each population. Preliminary tests indicated no significant difference in susceptibility between males and females, separation of sexes was therefore not necessary.

Serial dilutions of the insecticides (in acetone) were made on the basis of wt/vol (Al) and expressed as $\mu \mathrm{g} / \mu \mathrm{l}$. The symmetric design recommended by Finney (1971) for precise estimation of the $L_{50}$ was used in all studies. Six to seven different concentrations of the insecticides were tested on 20 to 25 insects at a time. The entire procedure was replicated four times.

Adults were treated as described by Osman et al. (In press). Mortality was recorded $48 \mathrm{~h}$ after treatment. Failure to change position within $30 \mathrm{~s}$ after gentle probing with a blunt probe was used as the criterion for death.

(ii) Larvae. Third instars weighing $13 \pm 1 \mathrm{mg}$ were used in this bioassay. The bioassay chambers consisted of glass Petri dishes $(10$ by $75 \mathrm{~mm}$ ) lined with one layer of filter paper (Whatman No. 1 , $90 \mathrm{~mm})$. A uniform amount $(1.5 \mathrm{ml})$ of the desired concentration was applied onto the filter paper lining the Petridish. The dish was then tilted slightly and rotated slowly to ensure uniform coverage of the insecticide solution on the filter paper. Treated dishes were air-dried for 15 minutes before larvae were placed in them. Ten larvae per dish were used in preliminary (range-finding) studies and 20 to 30 larvae per dish were used in each bioassay. Two h after exposure to the chemical, the larvae were transferred to cartons containing the diet and the rearing procedure outlined previously was used.

Reversion of Resistance to Permethrin in Field Strains. Two colonies of pink bollworm from populations collected in Yuma and Marana, Arizona, were established in the laboratory. Monitoring was performed on adults. The reversion study with the Marana strain was initiated in the $F_{1}$ generation, but due to the difficulties (low fecundity, low viability) encountered in establishing the Yuma strain in the laboratory, monitoring was not initiated until the third generation. Monitoring was continued until a stable level of susceptibility was attained.

Laboratory Selection for Resistance to Permethrin and Azinphosmethyl. The Marana strain was selected for resistance to permethrin and azinphosmethyl at both larval and adult stages. The strain 
had been reared in the laboratory for four generations before any insecticide treatment.

Selection at the Larral Stage. The bioassay procedure described for larvae was used in this study. Two lines of the Marana strain were selected separately with permethrin and azinphosmethyl. The lariae were subjected to a selection pressure of $\mathrm{LC}_{50}$ to $\mathrm{LC}_{90}$ during the period of study. To monitor the development of resistance in adults topically, a portion of the larval population was reared to adulthood, without exposure to insecticide, every two to three generations. Observations on the progression of resistance in larval generations were based on alterations in selecting doses. The experiment was continued for a total of 14 to 16 generations.

Selection at the Adult Stage. A study on selection for resistance at the adult stage was done with the Marana strain. Both permethrin and azinphosmethyl were used as selection agents on this strain and the development of resistance was monitored every two to three generations. Survivors from the application of the highest dose served as parent stock for the succeeding generations. In generations for which baseline data were not obtained, adults were treated topically to give 70 to $80 \%$ mortality. Selection was continued for 14 to 16 generations.

\section{Results and Discussion}

Reversion of Permethrin Resistance. Both the Yuma and Marana populations exhibited similar trends in their fairly quick reversion to susceptibility (Table 1). When the Marana and the Yuma field strains were released from selection pressures, they lost resistance to permethrin and reverted to susceptibility in four - and five generations, respectively. The $L D_{50}$ 's decreased significantly by the second and third generations. By the $F_{4}$ generation the Marana and the Yuma populations showed about 3- and 8-fold increase in susceptibility, respectively. In fact, no significant fluctuation occurred beyond the $F_{4}$ generation in the Marana strain and the $F_{5}$ generation of the Yuma strain. We conclude that evaluation of resistance in the pink bollworm collected from the field and reared in the laboratory should be done on the $F_{1}$ generation.

Selection with Azinphosmethyl. Continuous selection of both larval and adult pink bollworms of the Marana strain with azinphosmethyl produced less than two-fold tolerance in adult moths by the end of the $F_{14}$ generation. Data for the $F_{1}$ generation were used as reference points to follow the progression of resistance.

Table 2 shou.s the selection for and progression of resistance in the larvae. For selections applied to the larval stage, dose-mortality responses obtained on the adult moths are presented in Table 3. Clearly, resistance developed very slowly in adults and a tolerance ratio of only 1.9 was obtained by the $F_{14}$ generation. Thus, selection on larvae produced $<2$-fold tolerance in adults. On the other hand, the larvae exhibited a much higher tolerance to azinphosmethyl by the $F_{15}$ generation (Table 2 ).

Selection for azinphosmethyl resistance at the adult stage at about an $L D_{80}$ produced only 1.6 -fold resistance by the $F_{14}$ generation (Table 3 ). The highest resistance ratio (1.9) was observed in the $F_{12}$ generation. We found that even after more than 20 years of field exposure to azinphosmethyl, field populations of pink bollworm from Arizona exhibit only low levels of tolerance to azinphosmethy! (Osman et al. in press).

Selection with Permethrin. The selection for and progression of resistance to permethrin of larvae through 15 generations (Table 2) produced a 9.7 -fold increase in resistance of adults by the end of the study (Table 4). The highest level of resistance $\left(13.2\right.$-fold) occurred in the $F_{14}$ generation. The progression of resistance was gradual during most of the selection process. By the $F_{14}$ generation, the resistance ratio increased about 3.5 -fold relative to the $F_{12}$ generation. Larval selection produced a much higher level of tolerance in larvae by the end of the study, compared with the maximum of 9.7 - 
fold increase observed in adults (Table 4). Higher slope values obtained in $F_{12}$ through $F_{16}$ generations indicated an increase in homogeneity in later generations.

Results of selection for permethrin resistance in adults are presented in Table 4 . By the $F_{14}$ generation, resistance increased by 8.8 -fold. Values of the slopes indicated that a population that was apparently heterogeneous at the beginning of the study tended to become relatively more homozygous as selection progressed. The results of these studies indicate that resistance develops more rapidly in larvae than in adult pink bollworms. This difference in resistance development appeared more clearly: with azinphosmethyl. Unlike most other lepidopterous pests, control measures on the pink bollworm are directed against the adult moth for biological and ecological reasons. Although the results of these studies show that larvae are capable of developing higher levels of resistance, especially 10 azinphosmethyl, they are not selected under field situations (Osman et al. In press). Hence biological and ecological features may have contributed to the slow evolution of resistance in the pink bolluorm relative to some other lepidopterous pests.

\section{Literature Cited}

Bariola, L. A. 1985. Evidence of resistance to synthetic pyrethroids in field populations of pink bollw'orm in southern California, p.138. In Proceedings of the beltwide cotton production and research conference, Jan. 6-11, 1985. New Orleans, LA.

Bartlett. A. C. \& W. W. Wolf. 1985. Pectinophora gossypiella, pp.415-430. In R. F. Moore \& P. Singh [eds.], Handbook of insect rearing, vol. 2. Elsevier Scientific Publishing Co.. Amsterdam.

Carruth, L. A. \&. L. Moore. 1973. Cotton scouting and pesticide use in Eastern Arizona. J. Econ. Entomol. 66: 187-190.

Finney, D. J. 1971. Probit analysis, 3rd ed. Cambridge University Press, London.

Haynes, K. F., T. A. Miller, R. T. Staten, W. G. Li \& T. C. Baker. 1986. Monitoring insecticide resistance with insect pheromones. Experimentia. 42: 1293-1295.

Osman, A. A., T. F. Watson \& S. Sivasupramaniam. In press. Susceptibility of field populations of pink bollworm (Lepidoptera: Gelechiidae) to azinphosmethyl and permethrin and synergism of permethrin. J. Econ. Entomol. 
Table 1. Reversion of permethrin resistance in pink bollworm strains following relaxation of insecticidal pressure

\begin{tabular}{|c|c|c|c|c|c|c|c|c|c|}
\hline \multicolumn{5}{|c|}{ Marana Strain } & \multicolumn{4}{|c|}{ Yuma Strain } & \multirow[b]{2}{*}{$R^{c}$} \\
\hline$G_{e n}{ }^{a}$ & $n$ & $\begin{array}{l}\text { Slope } \\
( \pm S E)\end{array}$ & $\begin{array}{l}L D_{50}{ }^{b} \\
(95 \% C L)\end{array}$ & $\mathbf{R R}^{\mathrm{e}}$ & Gen* & $\mathrm{n}$ & $\begin{array}{l}\text { Slope } \\
( \pm S E)\end{array}$ & $\begin{array}{c}L_{50}^{b} \\
(95 \% C L)\end{array}$ & \\
\hline $\mathrm{F}_{0}$ & 600 & $\begin{array}{c}2.37 \\
( \pm 0.22)\end{array}$ & $\begin{array}{l}4.5 d \\
(4.0-5.1)\end{array}$ & 1.0 & $F_{0}$ & 500 & $\begin{array}{l}4.86 \\
( \pm 0.41)\end{array}$ & $\begin{array}{l}16.2 \mathrm{~d} \\
(15.5-17.0)\end{array}$ & 1.0 \\
\hline$F_{1}$ & 500 & $\begin{array}{l}2.18 \\
( \pm 0.34)\end{array}$ & $\begin{array}{l}3.7 \mathrm{~cd} \\
(3.1-4.3)\end{array}$ & 0.8 & $F_{3}$ & 400 & $\begin{array}{l}2.40 \\
( \pm 0.34)\end{array}$ & $\begin{array}{l}6.4 c \\
(5.3-7.4)\end{array}$ & 0.4 \\
\hline $\mathrm{F}_{2}$ & 500 & $\begin{array}{l}2.92 \\
( \pm 0.37)\end{array}$ & $\begin{array}{l}3.1 b c \\
(2.5-3.5)\end{array}$ & 0.7 & $F_{4}$ & 400 & $\begin{array}{c}3.40 \\
( \pm 0.37)\end{array}$ & $\begin{array}{l}3.2 \mathrm{~b} \\
(2.9-3.6)\end{array}$ & 0.2 \\
\hline $\mathrm{F}_{3}$ & 600 & $\begin{array}{c}3.67 \\
( \pm 0.43)\end{array}$ & $\begin{array}{l}2.8 \mathrm{~b} \\
(2.5-3.0)\end{array}$ & 0.6 & $F_{3}$ & 400 & $\begin{array}{c}3.14 \\
( \pm 0.42)\end{array}$ & $\begin{array}{c}2.4 \mathrm{a} \\
(2.1-2.6)\end{array}$ & 0.2 \\
\hline$F_{4}$ & 400 & $\begin{array}{c}3.45 \\
( \pm 0.43)\end{array}$ & $\begin{array}{l}2.0 \mathrm{a} \\
(1.8-2.2)\end{array}$ & 0.4 & $\mathrm{~F}_{7}$ & 400 & $\begin{array}{c}3.70 \\
( \pm 0.40)\end{array}$ & $\begin{array}{l}2.4 \mathrm{a} \\
(2.2-2.7)\end{array}$ & 0.2 \\
\hline $\mathrm{F}_{6}$ & 500 & $\begin{array}{c}3.42 \\
( \pm 0.42)\end{array}$ & $\begin{array}{l}2.1 \mathrm{a} \\
(1.9-2.3)\end{array}$ & 0.5 & & & & & \\
\hline
\end{tabular}

a Filial generation.

${ }^{b} \mu \mathrm{g} / \mathrm{g}$. Values followed by the same letter are not significantly different based on failure of $95 \% \mathrm{CL}$ to overlap.

' $R$ R: Resistance ratio $=L D_{50}$ of $F_{x} / L D_{50}$ of $F_{0}$. 
Table 2. Selection and progression of resistance to azinphosmethyl and permethrin of 3 rd instar PBW

\begin{tabular}{|c|c|c|c|c|}
\hline \multicolumn{3}{|c|}{ Azinphosmethyl } & \multicolumn{2}{|c|}{ Permethrin } \\
\hline Generation & Concentration & $\%$ Sel. Press. & Concentration & $\%$ Sel. Press. \\
\hline $\begin{array}{l}F_{1} \\
F_{2} \\
F_{3} \\
F_{4} \\
F_{5} \\
F_{6} \\
F_{7} \\
F_{8} \\
F_{9} \\
F_{10} \\
F_{11} \\
F_{12} \\
F_{13} \\
F_{14}^{14} \\
F_{15}\end{array}$ & $\begin{array}{c}0.3-0.5 \\
0.3-0.7 \\
0.4-0.6 \\
0.5-1.5 \\
0.7-2.0 \\
1.0-2.5 \\
1.6 \\
2.5-3.0 \\
2.0-3.0 \\
3.0-3.5 \\
3.0-4.5 \\
3.0-4.0 \\
4.5-5.0 \\
4.0-6.0 \\
6.0\end{array}$ & $\begin{array}{l}72 \\
94 \\
53 \\
75 \\
91 \\
59 \\
69 \\
82 \\
65 \\
71 \\
92 \\
83 \\
79 \\
90 \\
82\end{array}$ & $\begin{array}{c}0.05-0.20 \\
0.08-0.20 \\
0.10-0.25 \\
0.15-0.25 \\
0.15-0.25 \\
0.25 \\
0.30-0.40 \\
0.50 \\
0.40-1.0 \\
1.0 \\
1.0-2.0 \\
1.5 \\
1.0-2.0 \\
1.5-3.0 \\
3.0\end{array}$ & $\begin{array}{l}64 \\
67 \\
61 \\
92 \\
57 \\
63 \\
71 \\
76 \\
83 \\
58 \\
89 \\
81 \\
76 \\
68 \\
73\end{array}$ \\
\hline
\end{tabular}

a $\mu \mathrm{g} / \mu \mathrm{l}$.

b Larvae selected for resistance using the dish treatment procedure.

Table 3. Responses of adult PBW subjected to azinphosmethyl pressure for several generations.

\begin{tabular}{|c|c|c|c|c|c|c|c|}
\hline \multicolumn{4}{|c|}{ Selection on 3rd Larval Instar } & \multicolumn{4}{|c|}{ Adult Selection } \\
\hline $\begin{array}{c}\operatorname{Gen}^{3}- \\
n\end{array}$ & Slope & $\begin{array}{l}\mathrm{LD}_{50}{ }^{\circ} \\
( \pm \mathrm{SE})\end{array}$ & $\begin{array}{l}R^{c} \\
(95 \% C L)\end{array}$ & $\mathrm{n}$ & Slope & $\begin{array}{l}L_{D_{50}} b \\
( \pm S E)\end{array}$ & $\begin{array}{l}R R^{c} \\
(95 \% C L)\end{array}$ \\
\hline$\overline{F_{1}} 500$ & $\begin{array}{c}7.23 \\
( \pm 0.88)\end{array}$ & $\begin{array}{l}20.9 a \\
(20.0-22.1)\end{array}$ & 1.0 & 520 & $\begin{array}{c}7.23 \\
( \pm 0.91)\end{array}$ & $\begin{array}{c}21.1 \mathrm{a} \\
(19.8-22.0)\end{array}$ & 1.0 \\
\hline$F_{3} 400$ & $\begin{array}{c}7.71 \\
( \pm 0.96)\end{array}$ & $\begin{array}{c}21.7 \mathrm{a} \\
(20.6-22.8)\end{array}$ & 1.0 & 420 & $\begin{array}{c}6.82 \\
( \pm 0.70)\end{array}$ & $\begin{array}{c}22.3 \mathrm{a} \\
(21.3-23.4)\end{array}$ & 1.1 \\
\hline$F_{5} 425$ & $\begin{array}{c}5.44 \\
( \pm 0.65)\end{array}$ & $\begin{array}{c}22.0 \mathrm{a} \\
(20.6-23.3)\end{array}$ & 1.1 & 460 & $\begin{array}{l}7.96 \\
( \pm 0.03)\end{array}$ & $\begin{array}{c}27.4 b \\
(26.2-28.6)\end{array}$ & 1.3 \\
\hline$F_{7} 450$ & $\begin{array}{c}4.17 \\
( \pm 0.67)\end{array}$ & $\begin{array}{c}29.9 b c \\
(27.5-32.6)\end{array}$ & 1.4 & 500 & $\begin{array}{c}6.25 \\
( \pm 0.81)\end{array}$ & $\begin{array}{c}25.8 b \\
(24.1-27.1)\end{array}$ & 1.2 \\
\hline$F_{9} 475$ & $\begin{array}{c}5.15 \\
( \pm 0.67)\end{array}$ & $\begin{array}{c}26.7 \mathrm{~b} \\
(24.9-28.3)\end{array}$ & 1.3 & 400 & $\begin{array}{c}9.33 \\
( \pm 0.07)\end{array}$ & $\begin{array}{c}26.4 b \\
(25.4-27.4)\end{array}$ & 1.3 \\
\hline$F_{12} 400$ & $\begin{array}{c}4.97 \\
( \pm 0.68)\end{array}$ & $\begin{array}{c}34.1 c \\
(31.6-36.5)\end{array}$ & 1.6 & 440 & $\begin{array}{c}5.59 \\
( \pm 0.84)\end{array}$ & $\begin{array}{c}40.7 d \\
(38.6-43.5)\end{array}$ & 1.9 \\
\hline$F_{14} 274$ & $\begin{array}{c}6.13 \\
( \pm 0.85)\end{array}$ & $\begin{array}{c}40.6 d \\
(38.4-43.2)\end{array}$ & 1.9 & 400 & $\begin{array}{c}5.06 \\
( \pm 0.64)\end{array}$ & $\begin{array}{c}33.4 c \\
(31.4-35.5)\end{array}$ & 1.6 \\
\hline
\end{tabular}

a, $b, c^{c}$ See footnote table 1. 
Table 4. Responses of adult pink bollworms subjected to permethrin pressure for several generations

\begin{tabular}{|c|c|c|c|c|c|c|c|}
\hline \multirow{3}{*}{$\begin{array}{c}\begin{array}{c}\text { Gen } \\
n\end{array} \\
F_{1} 475\end{array}$} & \multicolumn{3}{|c|}{ Selection on 3rd Instar Larvae } & \multicolumn{3}{|c|}{ Adult Selection } & \multirow[b]{2}{*}{$R^{e}$} \\
\hline & $\begin{array}{l}\text { Slope } \\
( \pm S E)\end{array}$ & $\begin{array}{l}L_{50}^{b} \\
(95 \% \mathrm{CL})\end{array}$ & $R^{e}$ & $\stackrel{n}{( \pm S E)}$ & $\begin{array}{l}\text { Slope } \\
(95 \% \mathrm{CL})\end{array}$ & $L D_{50}^{b}$ & \\
\hline & $\begin{array}{c}3.45 \\
( \pm 0.42)\end{array}$ & $\begin{array}{c}2.0 \mathrm{a} \\
(0.8-2.2)\end{array}$ & 1.0 & 480 & $\begin{array}{c}3.45 \\
( \pm 0.42)\end{array}$ & $\begin{array}{c}2.0 \mathrm{a} \\
(1.7-2.2)\end{array}$ & 1.0 \\
\hline$F_{3} 420$ & $\begin{array}{c}3.19 \\
( \pm 0.35)\end{array}$ & $\begin{array}{c}2.3 \mathrm{ab} \\
(2.1-2.5)\end{array}$ & 1.2 & 420 & $\begin{array}{c}2.57 \\
( \pm 0.35)\end{array}$ & $\begin{array}{c}3.2 b \\
(2.7-3.6)\end{array}$ & 1.6 \\
\hline$F_{3} 480$ & $\begin{array}{c}2.98 \\
( \pm 0.44)\end{array}$ & $\begin{array}{c}2.5 b \\
(2.2-2.8)\end{array}$ & 1.3 & 460 & $\begin{array}{c}2.64 \\
( \pm 0.49)\end{array}$ & $\begin{array}{r}2.5 \mathrm{ab} \\
(2.1-2.8)\end{array}$ & 1.3 \\
\hline$F_{7} 500$ & $\begin{array}{c}3.00 \\
( \pm 0.46)\end{array}$ & $\begin{array}{c}3.4 c \\
(2.9-3.8)\end{array}$ & 1.7 & 430 & $\begin{array}{c}2.70 \\
( \pm 0.37)\end{array}$ & $\begin{array}{c}5.0 c \\
(4.3-5.7)\end{array}$ & 2.6 \\
\hline$F_{9} 400$ & $\begin{array}{c}3.27 \\
( \pm 0.53)\end{array}$ & $\begin{array}{c}7.9 d \\
(7.1-8.8)\end{array}$ & 4.0 & 500 & $\begin{array}{c}3.22 \\
( \pm 0.39)\end{array}$ & $\begin{array}{c}7.0 d \\
(6.3-7.8)\end{array}$ & 3.6 \\
\hline$F_{12} 400$ & $\begin{array}{c}5.53 \\
( \pm 0.55)\end{array}$ & $\begin{array}{l}7.5 d \\
(7.1-8.0)\end{array}$ & 3.8 & 400 & $\begin{array}{c}5.03 \\
( \pm 0.52)\end{array}$ & $\begin{array}{c}14.8 \mathrm{e} \\
(13.8-15.9)\end{array}$ & 7.6 \\
\hline$F_{14} 445$ & $\begin{array}{c}4.56 \\
( \pm 0.69)\end{array}$ & $\begin{array}{l}26.0 f \\
(14.2-28.5)\end{array}$ & 13.2 & 420 & $\begin{array}{c}5.16 \\
( \pm 0.56)\end{array}$ & $\begin{array}{c}17.3 f \\
(16.2-18.5)\end{array}$ & 8.8 \\
\hline$F_{16} 450$ & $\begin{array}{c}4.18 \\
( \pm 0.49)\end{array}$ & $\begin{array}{l}19.2 \mathrm{e} \\
(17.6-20.8)\end{array}$ & 9.7 & -- & -- & -- & - \\
\hline
\end{tabular}

a Filial generation.

b $\mu \mathrm{g} / \mathrm{g}$. Values followed by the same letter are not significantly different based on failure of $95 \% \mathrm{CL}$ 10 overlap.

CRR: Resistance ratio $=L D_{30}$ of $F_{x} / L D_{30}$ of $F_{0}$. 